\title{
The Effects of the Blending Condition on the Morphology, Crystallinity, and Thermal Stability of Cellulose Microfibers Obtained from Bagasse
}

\author{
Romi Sukmawan ${ }^{1,}$, Lestari Hetalesi Saputri ${ }^{2}$, Rochmadi ${ }^{3}$, and Heru Santoso Budi Rochardjo ${ }^{4}$ \\ ${ }^{1}$ Department of Mechanical Engineering, Politeknik Lembaga Pendidikan Perkebunan, \\ Jl. LPP 1 A, Balapan, Yogyakarta 11840, Indonesia \\ ${ }^{2}$ Department of Chemical Engineering, Politeknik Lembaga Pendidikan Perkebunan, \\ Jl. LPP 1 A, Balapan, Yogyakarta 11840, Indonesia \\ ${ }^{3}$ Department of Chemical Engineering, Faculty of Engineering, Universitas Gadjah Mada, \\ Jl. Grafika No. 2, Yogyakarta 55281, Indonesia \\ ${ }^{4}$ Department of Mechanical and Industrial Engineering, Faculty of Engineering, Universitas Gadjah Mada, \\ Jl. Grafika No. 2, Yogyakarta 55281, Indonesia
}

\section{*Corresponding author: \\ email:romi_s@politeknik-lpp.ac.id}

Received: December 8, 2017

Accepted: February 27, 2018

DOI: $10.22146 /$ ijc. 31051

\begin{abstract}
In this study, cellulose microfibers were isolated from bagasse fibers in three stages. Initially, the fibers were treated with $5 \mathrm{wt} . \% \mathrm{NaOH}$ solution followed by bleaching with 5 wt.\% $\mathrm{H}_{2} \mathrm{O}_{2}$ in an alkali condition ( $\mathrm{pH}$ 11) to remove hemicelluloses and lignin. Whole cellulosic fibers were obtained by mechanically separating the fibers using a modified kitchen blender to produce cellulose microfibers. Morphological (Scanning Electron Microscopy (SEM)) and structural analysis of the treated fiber was performed using Fourier Transformed Infrared (FTIR) spectroscopy and X-ray Diffraction (XRD). Morphological characterization identified that the diameter of the fibers varied between $20 \mathrm{~nm}$ to $20 \mu \mathrm{m}$ and the FTIR analysis demonstrated that the treatments resulted in the gradual removal of lignin and hemicelluloses from the fiber. Furthermore, the XRD studies revealed that the combination of the chemical and mechanical treatment is an effective way to increase purity of cellulose (removal of amorphous lignin and hemicellulose) and break down the microfiber into shorter crystalline parts with higher crystallinity (77.25\%) than raw bagasse (40.54\%). Accordingly, changing the agitation time revealed that the cellulose crystallite size in the sample varied slightly with agitation time by using a blender $(3.35 \mathrm{~nm})$. Finally, the higher crystallinity and crystallite size improved the thermal stability of the cellulose microfiber confirming their suitability in the manufacturing biomaterial composites.
\end{abstract}

Keywords: bagasse; cellulose microfibers; kitchen blender; agitation; biomaterial composites

\section{- INTRODUCTION}

Researchers are focusing on the preparation and utilization of microfibrillated cellulose (MFC) to produce high-performance nanocomposites given their high mechanical properties, renewability, and high surface area to volume ratios. Furthermore, with the combination of bioplastic matrix, these materials can be made entirely environmentally friendly.
Cellulose fiber is acquired from a variety of sources, which include grasses (bamboo, bagasse, rice etc.), leaf fibers (banana, pineapple, sisal etc.), wood (hardwood and softwood), seed fibers (coconut, coir, cotton etc.), bast fibers (flax, ramie, hemp, jute etc.), marine animals (tunicate), fungi, algae, invertebrate and bacteria [1-2]. Accordingly, cellulose fiber can be converted to different nanostructures with various 
physical properties, depending on the cellulose source and the production method. The primary source of MFC has been wood pulp fibers, subjected to mechanical treatment to produce nanofibers. MFC production methods consist of several operational stages by specialized devices requiring high energy consumption. Notably, less contain of lignin make non-wood plants receiving increasing attention as potential sources of cellulose and consequently, purification processes of the fiber are much easier and avoid damage to the cellulose. Moreover, it can reduce energy consumption for fibrillation of such cellulose.

Bagasse is a type of non-wood plant obtained after sucrose is extracted from the sugar cane plant. The fiber is insoluble in water consisting mostly of cellulose, hemicellulose, and lignin and has high cellulose content, which is easily isolated from other elements such as, hemicellulose and lignin by delignification and bleaching processes.

The mechanical disintegration method (e.g. highpressure homogenizer, microfluidizer, grinder, twin screw kneader, ball mill, and mechanical stirrer) has been introduced as one of the methods to facilitate the disintegration of cellulose into nanofibers [3]. However, many methods are facing difficulties given the mechanical force required to produce nanofibrillation, which can potentially lead to fiber damage, rather than elementary fibril disintegration. Consequently, it further produces MFC with a low degree of crystallinity, and aspect ratio resulting in relatively weak mechanical properties of the fiber. The combination of the chemical pre-treatment and mechanical disintegration methods using blender have been introduced as one of the many methods to facilitate the disintegration of cellulose into nanofibers and in-turn, reduce overall energy consumption. Uetani and Yano successfully used a high-speed blender to produce cellulose nanofibers with a diameter of $15-20 \mathrm{~nm}$ from bleached softwood pulp by blending at various cellulose concentrations (up $1.5 \mathrm{wt} . \%$ ), with stirring speeds of $37,000,10,000$, and 5,000 rpm, respectively, and with a duration time up to $2 \mathrm{~h}$ [4]. Chaker et al. investigated the production of cellulose nanofiber by blending of $2 \%$ cellulose suspension for $20 \mathrm{~min}$ and the result was comparable to a suspension passed 10 times at $600 \mathrm{bar}$ in homogenizer [5]. Jiang and Hsieh investigated blending of cellulose suspension from rice straw at $37,000 \mathrm{rpm}$ for various durations up to $2 \mathrm{~h}$ to obtain cellulose nanofiber having a diameter of $2.7 \mathrm{~nm}$, a length of $100-200 \mathrm{~nm}$, the diameter of $8.5 \mathrm{~nm}$ and length of several micrometers [6]. Nakagaito et al. improved the design of the blender container to reduce the blending time, resulting in the nanofibrillation treatment process being achieved in a much shorter timeframe [7]. However, no report has been found on the effect of using six cutting blades rotating of the blender on the preparation of MFC from bagasse fibers.

In this study, modifying an original $2 \mathrm{~L}$ container (bottle) by reducing its capacity by half (i.e. $1 \mathrm{~L}$ ) as introduced by Nakagaito et al. [7] and using a stainless steel six cutting blades rotating at the bottom of the blender bottle is proposed to optimize the fibrillation of bagasse fiber. The effect of the agitation time on surface topography and morphology were characterized using SEM, TEM, chemical and physical FTIR spectroscopy, $\mathrm{XRD}$, and thermal properties thermogravimetric analysis (TG and DTG). Image analysis of the resulting product was conducted using ImageJ software to investigate the diameter of the fibers' where it was observed that cellulose microfibers were obtained by using the combination of chemical and mechanical treatments which would be suitable in manufacturing biocomposites for various applications.

\section{- EXPERIMENTAL SECTION}

\section{Materials}

Sugarcane bagasse was obtained from the Madu Baru sugar factory (Yogyakarta, Indonesia). For pretreatment and bleaching of the fibers, sodium hydroxide $(\mathrm{NaOH})$ and hydrogen peroxide $\left(\mathrm{H}_{2} \mathrm{O}_{2}\right)$ solutions were used. A Philips HR2096 800 W (21,000 rpm) household blender was used for mechanical fibrillation.

\section{Instrumentation}

\section{Fourier transform infrared spectroscopy (FTIR)}

FTIR spectra were obtained using a Shimadzu IR Prestige 21 Fourier transform infrared spectrometer. The 
samples were analyzed in a spectral region between 4000 and $400 \mathrm{~cm}^{-1}$, at a resolution of $2 \mathrm{~cm}^{-1}$, performing 20 scans.

\section{Scanning electron microscopy (SEM)}

The morphological structure of bagasse fiber before and after chemical and mechanical treatment was investigated using a Scanning Electron Microscope (SEM), (JEOL Ltd., JSM-6510LA). The samples were placed on carbon tapes and coated with a thin layer of platinum using a Sputter Coater (JEOL Ltd., model JEC3000 FC).

\section{Transmission electron microscopy (TEM)}

The morphological structure of the cellulose nanofiber was investigated using a Transmission Electron Microscope (TEM), (JEOL Ltd., JEM-1400).

\section{Image analysis}

The dimensions of cellulose microfibers were measured using freely available (Freeware) ImageJ software (National Institute of Health (NIH), USA) for image analysis.

\section{Thermo gravimetric analysis (TGA)}

A DTG-60 Shimadzu was used to study the thermal behavior of the fibers as a function of their weight changes under a controlled atmosphere with an experimental condition of about $10.0 \mathrm{mg}$ of the sample, a heating rate of $10^{\circ} \mathrm{C} / \mathrm{min}$ using nitrogen as carrier gas.

\section{$X$-ray diffraction (XRD)}

$\mathrm{X}$-Ray diffraction measurements were performed using the Rigaku Miniflex 600 model system. The diffracted intensity of the $\mathrm{Cu} \mathrm{Ka}$ radiation $(0.154 \mathrm{~nm}$, $40 \mathrm{kV}$, and $15 \mathrm{~mA}$ ) was measured in the $2 \theta$ range of $0-70^{\circ}$, at a scanning speed of $3 \% \mathrm{~min}$, and the data recorded every $0.03^{\circ}$. The crystallinity index $\left(I_{\text {cr }}\right)$ was calculated according to the Segal method [8] applying Eq. 1:

$\% I_{\mathrm{cr}}=\frac{\mathrm{I}_{002}-\mathrm{I}_{\mathrm{am}}}{\mathrm{I}_{002}} \times 100$

where $I_{c r}$ is the crystalline index, $I_{002}$ is the maximum diffraction intensity corresponding to the 002 plane of cellulose crystals $\mathrm{I}\left(\mathrm{I}_{002}=22.5^{\circ}\right)$. The minimum intensity between the 200 and 110 peaks is the diffraction intensity for amorphous cellulose $\left(I_{\mathrm{am}}, 2 \theta=18^{\circ}\right.$ for cellulose $\left.\mathrm{I}\right)$.

The size (width) of the cellulose crystallite was estimated from the width of the peak at $2 \theta$ around $22.8^{\circ}$ at a half-height, applying the Debye-Scherrer [9] Eq. 2:

$\mathrm{D}($ crystallite size $)=\frac{\mathrm{K} \cdot \gamma}{\beta \cdot \cos \theta}$

where $K=0.9, \gamma=1.5406, \beta$ is the half-width after curve fitting, and $\theta$ is the Bragg angle for 200 reflections.

\section{Procedure}

\section{Fiber pre-treatment}

Previously ground (28-48 mesh) Bagasse fibers, were soaked in hot water at $80^{\circ} \mathrm{C}$ for $2 \mathrm{~h}$, to remove any dirt and other soluble contaminants before drying at $105^{\circ} \mathrm{C}$ in an oven for $6 \mathrm{~h}$. The dried fibers were then treated four times with a $\mathrm{NaOH}$ solution $5 \mathrm{wt} . \%$ at $75^{\circ} \mathrm{C}$ under constant agitation for $2 \mathrm{~h}$ to remove hemicelluloses and lignin. The weight ratio of the $\mathrm{NaOH}$ solution and bagasse was 20:1. The resulting pulp fibers were next washed using distilled water until the water reached the neutral $\mathrm{pH}$ level. Next, bleaching was performed twice at $80^{\circ} \mathrm{C}$ by adding the pulp fibers obtained previously, into preheated 5 wt. $\% \mathrm{H}_{2} \mathrm{O}_{2}$ under an alkaline condition (by adding the $\mathrm{NaOH}$ solution until the $\mathrm{pH}$ level was 11) followed by $1 \mathrm{~h}$ of mechanical stirring. The weight ratio of the $\mathrm{H}_{2} \mathrm{O}_{2}$ solution and pulp fiber was 20:1. After that, the bleached pulp fibers were washed with distilled water to achieve neutrality.

\section{Fibrillation process}

A suspension of pulp fibers was agitated using a household blender (Philips HR2096 800 W) with an operating speed of around $21,000 \mathrm{rpm}$, in which the stainless steel six cutting blades rotates in a recessed section at the bottom of a modified bottle, with a capacity of $1 \mathrm{~L}$.

Next, fibrillating $500 \mathrm{~mL}$ of bagasse fiber pulp aqueous suspension with a fiber content of $0.4 \mathrm{wt} . \%$ and agitation speed of $21,000 \mathrm{rpm}$ was carried out. The agitation time was set to $1,3,5,10,20$, and $30 \mathrm{~min}$, respectively. 


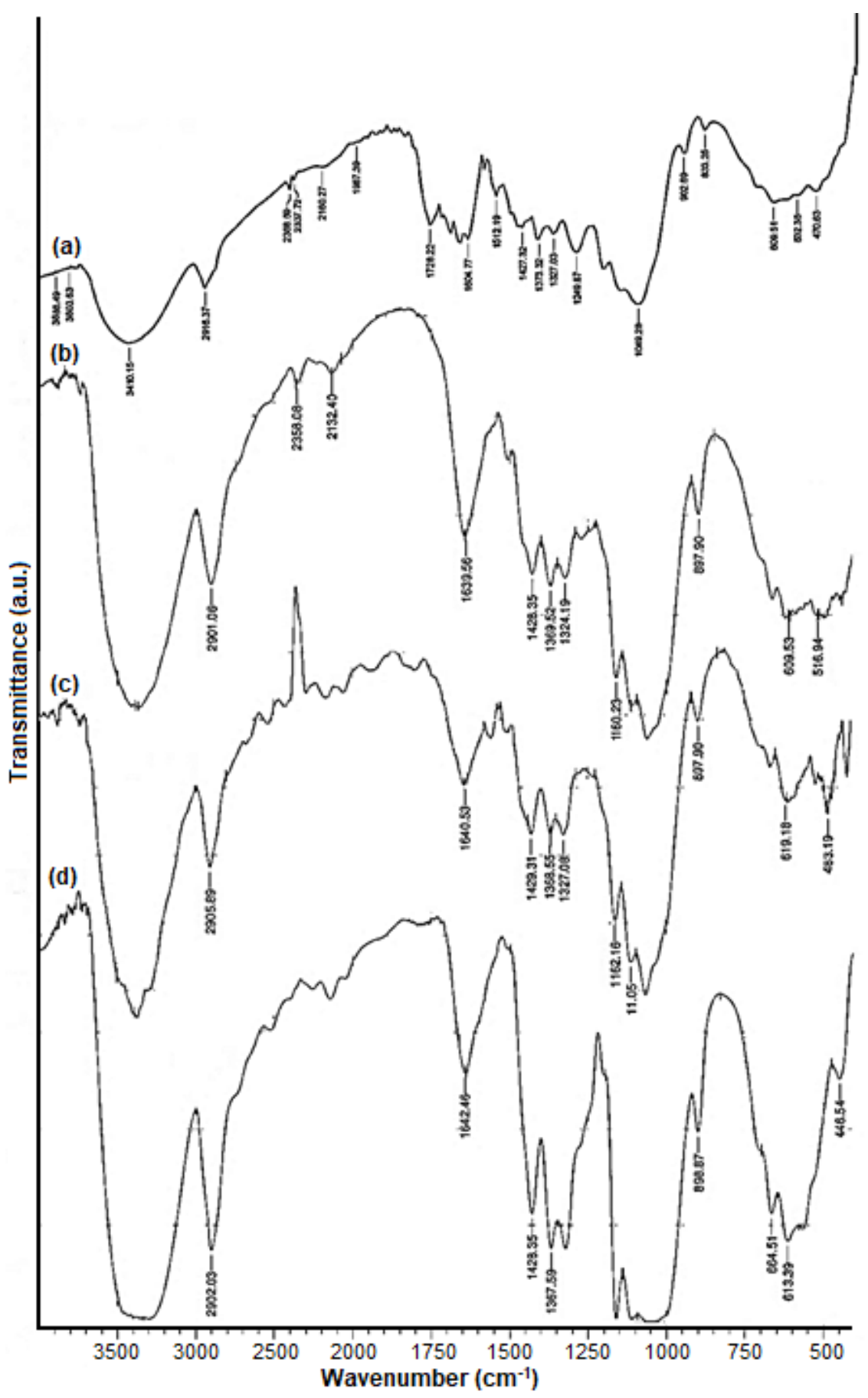

Fig 1. The FTIR spectra of (a) raw bagasse fiber (SCB); (b) alkali-treated fibers (ATF); (c) bleached fibers (BF); and (d) cellulose fibers agitated for $10 \mathrm{~min}$ (AG-10)

\section{- RESULTS AND DISCUSSION}

\section{FTIR Characterization}

Fig. 1 illustrates the absorption spectrum on the infrared region of the raw bagasse fiber (SCB), alkali- treated fibers (ATF), bleached fibers $(\mathrm{BF})$, and cellulose fibers agitated for $10 \mathrm{~min}$ (AG-10). In raw bagasse fiber, dominant peaks of $\mathrm{OH}$ - stretching and $\mathrm{CH}$ - stretching were observed at around 3400 and $2900 \mathrm{~cm}^{-1}$ respectively. A sharp peak at $1728 \mathrm{~cm}^{-1}$ is characteristic 
of the carbonyl band $(\mathrm{C}=\mathrm{O})$ of hemicellulose in sugarcane bagasse. The peak also indicates the ester linkage of the carboxylic group in the ferulic and $p$-coumaric acid of lignin and hemicellulose [10]. The peak at $1427 \mathrm{~cm}^{-1}$ is representative of the symmetric deformation of the $\mathrm{CH}_{2}$ group of cellulose, while the peak at $1249 \mathrm{~cm}^{-1}$ corresponds to the $\mathrm{C}-\mathrm{O}$ stretching of the aryl group in lignin. The absence of any peaks at 1728 and $1249 \mathrm{~cm}^{-1}$ for ATF and BF confirmed the removal of lignin and hemicellulose during the bleaching process [11-12].

However, the FTIR spectra of AG-10 displayed sharp peaks which are like the spectra observed in BF. The peak observed in the spectra of AG-10 in the area 1649$1634 \mathrm{~cm}^{-1}$ is because of the $\mathrm{O}-\mathrm{H}$ bending absorbing water [13]. Also, the band appearing at $1430-1420 \mathrm{~cm}^{-1}$ was due to the scissoring motion of cellulose I, $1369-1367 \mathrm{~cm}^{-1}$ (C-H bending), 1327 ( $\mathrm{CH}_{2}$ wagging), and $902-893 \mathrm{~cm}^{-1}$ (related with the cellulosic $\beta$-glycosidic linkages). The spectra bands observed at 1428 and $898 \mathrm{~cm}^{-1}$ displayed significant cellulose I content.

The crystallinity of the samples can be analyzed by FTIR spectral peaks [14]. The band at the $850-1500 \mathrm{~cm}^{-1}$ region is observed to be quite sensitive to the crystal structure of the cellulose of cellulosic material [15]. The spectral bands at $1420-1430$ and $893-897 \mathrm{~cm}^{-1}$ are extremely important to explain the crystal structure of cellulosic material [14]. The spectral ratio, $1420 / 893 \mathrm{~cm}^{-1}$ shows the index of crystallinity [12] or the Lateral Order Index (LOI) [16], and the spectral ratio $1375 / 2900 \mathrm{~cm}^{-1}$ represents the Total Crystallinity Index (TCI) [17-18].

Table 1. FTIR analysis parameters for calculated Lateral Order Index (LOI), and total crystallinity index (TCI)

\begin{tabular}{lcc}
\hline \multicolumn{1}{c}{ Sample } & LOI & TCI \\
& $\left(1430 / 897 \mathrm{~cm}^{-1}\right)$ & $\left(1375 / 2900 \mathrm{~cm}^{-1}\right)$ \\
\hline Sugarcane bagasse (SCB) & 1.2271 & 0.8386 \\
Bleached fibers (BF) & 1.1990 & 0.9509 \\
Cellulose fibres agitated for 10 min (AG-10) & 2.0751 & 0.9857 \\
\hline
\end{tabular}


Fig 2. Morphological investigation. Scanning electron micrographs of: (a) sugarcane bagasse fiber (SCB); (b) bleached fibers (BF); cellulose fibers agitated by blender for (c) 3 (AG-3), (d) 5 (AG-5), (e) 10 (AG-10), (f) 20 (AG-20), (g) 30 (AG-30) min, (SEM, $50 \mu \mathrm{m}$ scale); and (h) Transmission electron micrograph of the cellulose microfibers produced after blending for $10 \mathrm{~min}$ (TEM, $100 \mathrm{~nm}$ scale) 
The spectral ratio $1430 / 897 \mathrm{~cm}^{-1}$ in the cellulosic samples indicates the presence of cellulose I fraction [19]. The higher value of the LOI and TCI, suggest that the material contains a highly crystalline and ordered structure [20]. The spectral ratio $1430 / 897 \mathrm{~cm}^{-1}$ is low in the case of BF compared to SCB due to the chemical treatment carried out, which possibly disturbed the order of the structure. In the case of AG-10, it increases to a higher value which could be due to the removal of some amorphous of cellulose, while the spectral ratio $1375 / 2900 \mathrm{~cm}^{-1}$ increased from SCB to AG-10, as shown in Table 1.

\section{Morphological Investigation}

Fig. 2 displays the SEM photomicrographs of raw bagasse fibers (SCB) (Fig. 2(a)) and after bleaching with 5 vol.\% hydrogen peroxide $\left(\mathrm{H}_{2} \mathrm{O}_{2}\right)$ concentration at $\mathrm{pH} 11$ (BF) (Fig. 2(b)). The SCB were composed of individual fibers linked together by lignin. Fig. 2(b) displays the morphology of the BF during the bleaching treatment process, where the impurities, hemicellulose, and lignin were removed. In fact, most impurities around the fiber were removed, which in-turn, induced the separation of fiber bundles into individual fibers. Fig. 2(c-g) show that the fiber fraction was reduced and the fibrillated fraction increased with increasing agitation time.

Fig. 2(h) displays the fibrillated part of AG-10. The fiber dimensions isolated from the bagasse appeared to be less uniform from $20 \mathrm{~nm}$ to $20 \mu \mathrm{m}$. The fibers are often aggregated, and the individual fibers in the range of 7-20 $\mathrm{nm}$ (Fig. 2(h)). Microfibrils were also observed in AG-20 and AG-30 where fiber fraction was reduced, and the portion of microfibrils increased with increasing agitation time. The same phenomenon in the treated fiber by the blender for extended periods was also reported by Uetani and Yano [4].

\section{XRD Result}

Fig. 3 illustrates the XRD diffraction pattern of raw bagasse fiber, with chemically pre-treated $\mathrm{NaOH}$ and $\mathrm{NaOH}$, followed by bleaching with $\mathrm{H}_{2} \mathrm{O}_{2}$ treatment in an alkali condition ( $\mathrm{pH} 11)$.

These samples exhibited a peak $2 \theta=14.5$ to $15.3^{\circ}$ assigned to the (1-10) crystallographic plane; $2 \theta=15.7$ to $16.30^{\circ}$ assigned to the (110) crystallographic plane; $2 \theta$ $=21.90$ to $22.20^{\circ}$ assigned to the (220) crystallographic plane; and $2 \theta=34.6^{\circ}$ assigned to the (004) crystallographic plane of cellulose I [21-22].

Notably, the degree of crystallinity is one of the most important crystalline structure parameters. The rigidity of cellulose fibers increases with the increasing ratio of crystalline to amorphous regions [23]. The crystallinity index of the samples was calculated according to the Segal method (Eq. 1). The crystallinity index of the raw material (SCB) was calculated as $40.54 \%$ and increased in the case of pre-treated fibers (ATF) to $65.63 \%$ (due to the removal of hemicelluloses and lignin as the amorphous part). Moreover, it was $77.25 \%$ in the case of bleached fibers (BF) in which the remaining amorphous part was removed during the bleaching treatment. The results of the crystallinity degree obtained

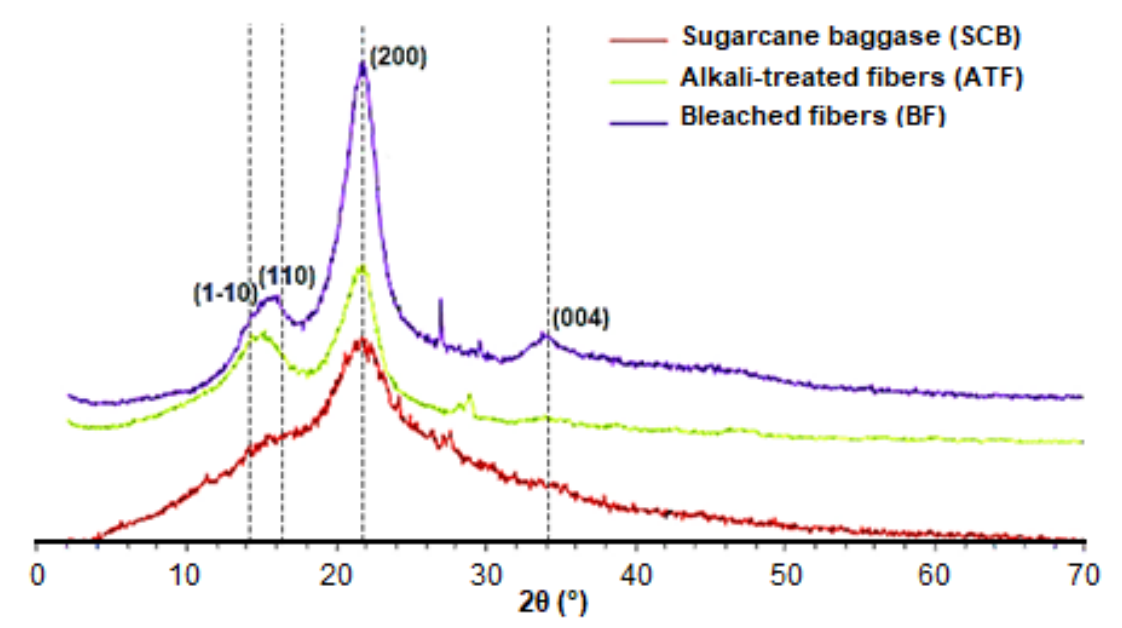

Fig 3. X-ray diffractogram of sugarcane bagasse as raw material (SCB), Alkali-treated fiber (ATF); and bleached fibers (BF) 


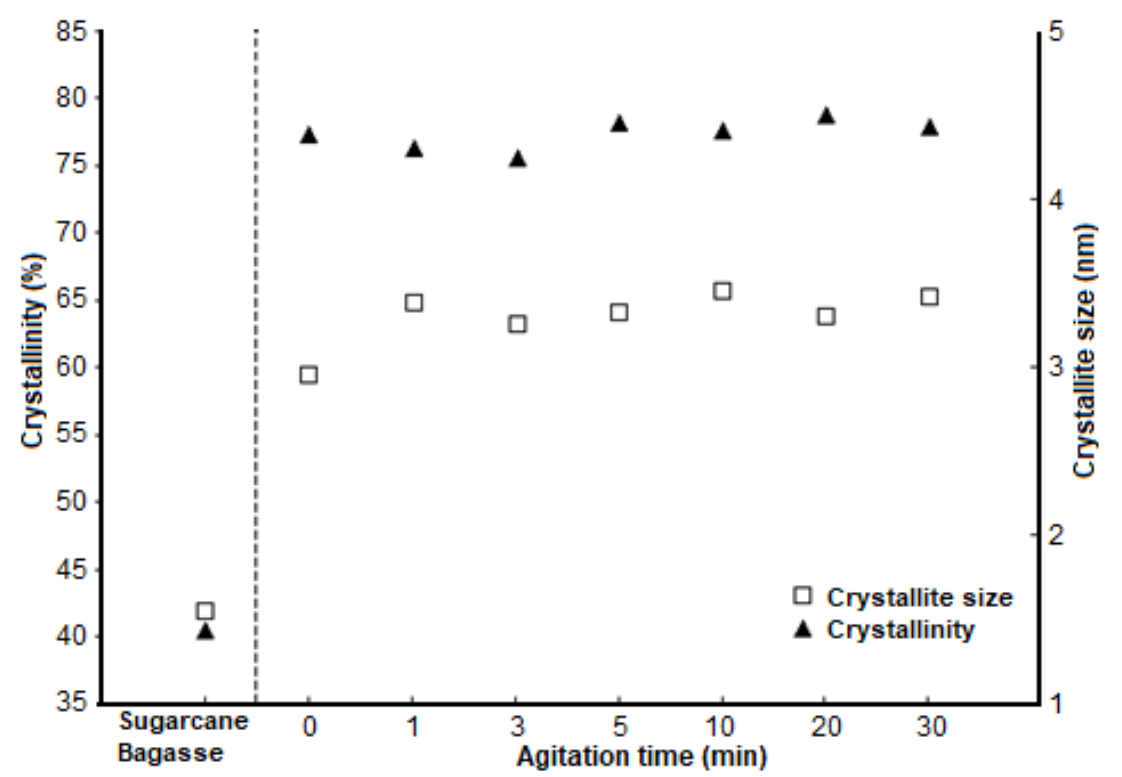

Fig 4. Crystallinity (\%) and crystallite size ( $\mathrm{nm}$ ) of cellulose fibers agitated by the blender

from the XRD analysis follows a similar trend as the results calculated using crystallinity analysis from the FTIR spectra.

The degree of crystallinity of untreated and treated fiber (as a function of the agitation time), (Fig. 4) was next examined to evaluate the effect of chemical and mechanical agitation. The increasing crystallinity following the bleaching treatment ( 0 min of agitation) to a higher value was due to the removal of significant parts like hemicellulose and lignin, from the amorphous components. Negligible difference was observed for any crystallinity of the fiber agitated for 1 to $30 \mathrm{~min}$ compared to the bleaching fiber, therefore, indicating that mechanical treatment using a blender does not adversely affect crystallinity. Processing of the XRD profiles applying Scherrer's equation (Eq. (2)) revealed that the cellulose crystallite size in the bleaching fiber $(2.96 \mathrm{~nm})$ drastically increased which is almost twice as high compared to untreated fiber $(1.55 \mathrm{~nm})$. Notwithstanding, the cellulose crystallite size found in the fiber increased slightly (around $3.35 \mathrm{~nm}$ ) with agitation using a blender. The marginal change in the crystal structure and crystallinity of the fiber is similar to the result reported by Uetani and Yano [4], confirming that fibrillation (mechanical treatment) by a blender causes less damage to the crystalline structure of cellulose.

\section{Thermogravimetric Result}

Fig. 5 displays the results of the thermal properties of SCB (Sugarcane bagasse) cellulose agitated for $1 \mathrm{~min}$ (AG-1), $10 \mathrm{~min}$ (AG-10), and $30 \mathrm{~min}$ (AG-30) respectively. An initial weight loss of approximately $4 \%$ is observed near $100{ }^{\circ} \mathrm{C}$ for all samples. The findings correspond to the vaporization and removal of moisture in the sample. Second step degradation started at $218^{\circ} \mathrm{C}$ for $\mathrm{SCB}$, at $253^{\circ} \mathrm{C}$ for $\mathrm{AG}-1$, at $268^{\circ} \mathrm{C}$ for $\mathrm{AG}-10$, and at $278^{\circ} \mathrm{C}$ for AG-30.

The increase in the thermal stability of $35^{\circ} \mathrm{C}$ for AG- $1,50{ }^{\circ} \mathrm{C}$ for AG- 10 and $60{ }^{\circ} \mathrm{C}$ for AG-30 compared to SCB was due to the removal of extractives from the bagasse biomass and/or removal of hemicellulose during chemical treatments, which decomposes before the cellulose and lignin, thereby resulting in high thermal stability.

Extractives are compounds that accelerate the degradation process of bagasse because it can promote the ignitability of bagasse at lower temperatures [21]. The TGA results showed that the order of thermal stability was SCB < AG-1 < AG-10 < AG-30. The maximum degradation temperature was 335 and $353{ }^{\circ} \mathrm{C}$ for SCB and AG-1, respectively, while the maximum peak degradation temperature of AG-10 and AG-30 was observed to be $356^{\circ} \mathrm{C}$. Accordingly, this means that 

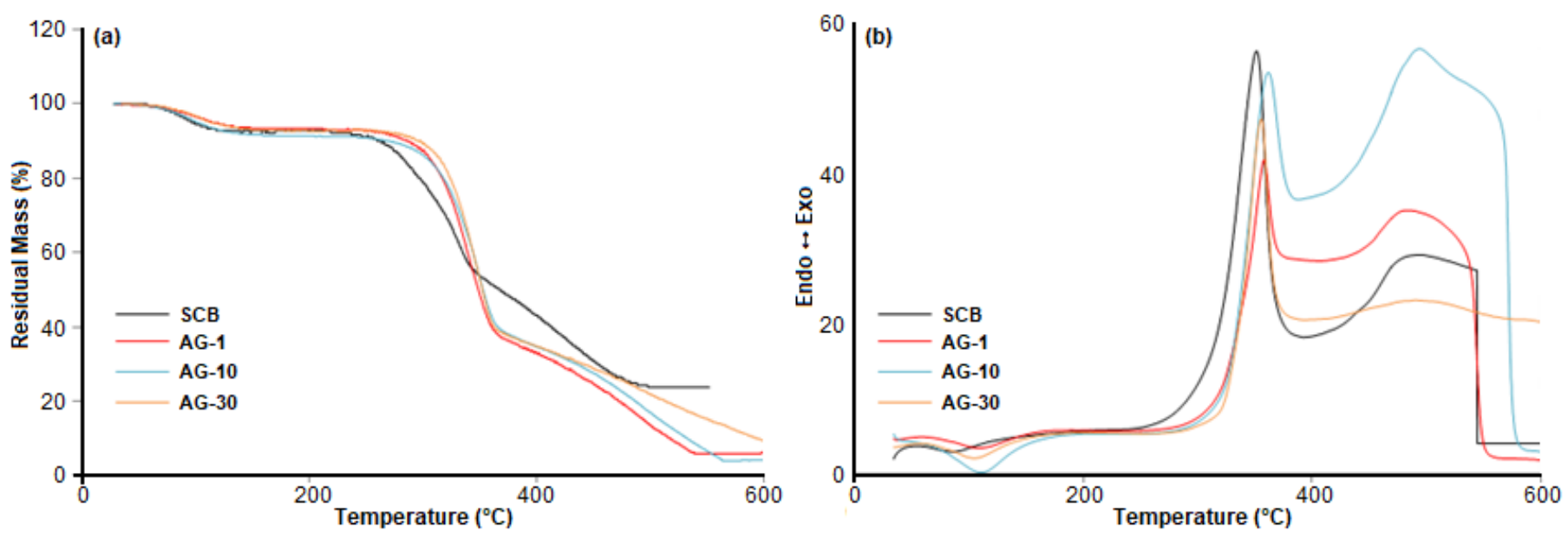

Fig 5. (a) TGA curves of sugarcane bagasse, and chemically purified cellulose treated by blender for 1 min (AG-1), 10 min (AG-10), and 30 min (AG-30); (b) DTG curves of sugarcane bagasse (SCB), and chemically purified cellulose treated by blender for $1 \mathrm{~min}$ (AG-1), $10 \mathrm{~min}$ (AG-10), and $30 \mathrm{~min}$ (AG-30)

chemical treatment followed by mechanical treatment of cellulose fibers acquires higher thermal stability than that of the raw bagasse sample. The treatment with $\mathrm{NaOH}$ and $\mathrm{H}_{2} \mathrm{O}_{2}$ removes the hemicellulose and lignin. A further increase in the thermal stability of AG-1, AG-10, and AG30 is also due to the slight increase in the crystalline structure of cellulose, which forms during mechanical treatment (colliding between fibers and the rotating blades of the blender). This is due to the separation of the individual cellulose fibers into sub-micron and/or nanofiber bundles. Moreover, it was also proven by the XRD profile analysis (Fig. 5), which showed that the cellulose agitated for $30 \mathrm{~min}$ (AG-30) sample had slightly higher crystallinity than the sample agitated for $10 \mathrm{~min}$ (AG-10) and $1 \mathrm{~min}$ (AG-1).

Accordingly, the result agrees with the findings of Kim et al. [24] where they found, that thermal decomposition of cellulose shifted to higher (elevated) temperatures with an increasing crystallinity index and crystallite size. The residue remained at $600{ }^{\circ} \mathrm{C}$ for raw bagasse, treated cellulose AG-1, AG-10, and AG-30 is 24, 6 , 4, and 9 wt.\%, respectively. The larger amount of residue at $600{ }^{\circ} \mathrm{C}$ observed in the raw bagasse fibers compared to the treated fibers was primarily may due to the presence of ash as well as the decomposition of lignin.

\section{- CONCLUSION}

Cellulose fibers were obtained from sugarcane bagasse fibers by the treatment of alkali and chlorine free bleaching and characterized by FTIR spectroscopy and microscopic observation. Cellulose microfibers were successfully extracted from the purified material by agitation using a modified household blender. The modification blender bottle with a capacity of 1 liter and six cutting blades rotating in a recessed section at the bottom of the bottle can reduce energy consumption for fibrillation of cellulose. It was also observed that mechanical treatment using a modified household blender does not adversely affect the crystallinity and crystal size of the fiber as the diameter is in the range of $20 \mathrm{~nm}$ to $20 \mu \mathrm{m}$. Thermogravimetric analysis confirmed the improved thermal stability for cellulose microfibers after chemical and mechanical treatments, resulting in greater potency in the manufacturing of biocomposites for various applications.

\section{- ACKNOWLEDGMENTS}

We would like to thank DRPM KEMRISTEKDIKTI RI for providing the financial support to conduct this research under contract number: DIPA042.06.1.401516/2017. 


\section{- REFERENCES}

[1] Varshney, V.K., and Naithani, S., 2011, "Chemical Functionalization of Cellulose Derived from Nonconventional Sources" in Cellulose Fibers: Bioand Nano- Polymer Composite, Kalia, S., Kaith, B.S., and Kaur, I. (Eds.), Springer, Berlin, 43-60.

[2] Wahyuningsih, K., Iriani, E.S., and Fahma, F., 2016, Utilization of cellulose from pineapple leaf fibers as nanofiller in polyvinyl alcohol-based film, Indones. J. Chem., 16 (2), 181-189.

[3] Nechyporchuk, O., Belgacem, M.N., and Bras, J., 2016, Production of cellulose nanofibrils: A review of recent advances, Ind. Crops Prod., 93, 2-25.

[4] Uetani, K., and Yano, H., 2011, Nanofibrillation of wood pulp using a high-speed blender, Biomacro molecules, 12 (2), 348-353.

[5] Chaker, A., Alila, S., Mutjé, P., Vilar, M.R., and Boufi, S., 2013, Key role of the hemicellulose content and the cell morphology on the nanofibrillation effective ness of cellulose pulps, Cellulose, 20 (6), 2863-2875.

[6] Jiang, F., and Hsieh, Y.L., 2013, Chemically and mechanically isolated nanocellulose and their selfassembled structures, Carbohydr. Polym., 95 (1), 32-40.

[7] Nakagaito, A.N., Ikenaga, K., and Takagi, H., 2015, Cellulose nanofibre extraction from grass by a modified kitchen blender, Mod. Phys. Lett. B, 29, 1540039.

[8] Segal, L., Creely, J.J., Martin, A.E., and Conrad, C.M., 1959, An empirical method for estimating the degree of crystallinity of native cellulose using the X-ray diffractometer, Text. Res. J., 29 (10), 786-794.

[9] Post, B., 1971, X-ray diffraction methods in polymer science, J. Polym. Sci., Part C: Polym. Lett., 9 (8), 635636.

[10] Joonobi, M., Harun, J., Shakeri, A., Misra, M., and Osman, K., 2009, Chemical composition, crystallinity and thermal degradation of bleached and unbleached Kenaf bast (Hibiscus cannabinus) pulp and nanofibres, BioResources, 4 (2), 626-639.

[11] Mothé, C.G., and de Miranda, I.C., 2009, Characterization of sugarcane and coconut fibers by thermal analysis and FTIR, J. Therm. Anal. Calorim., 97, 661-665.
[12] Rambabu, N., Panthapulakkal, S., Sain, M., and Dalai, A.K., 2016, Production of nanocellulose fibers from pinecone biomass: Evaluation and optimization of chemical and mechanical treatment conditions on mechanical properties of nanocellulose films, Ind. Crops Prod., 83, 746-754.

[13] Troedec, M., Sedan, D., Peyratout, C., Bonnet, J., Smith, A., Guinebretiere, R., Gloaguen, V., and Krausz, P., 2008, Influence of various chemical treatments on the composition and structure of hemp fibres, Composites Part A, 39 (3), 514-522.

[14] Carillo, F., Colom, X., Sunol, J.J., and Saurina J., 2004, Structure FTIR analysis and thermal characterization of lyocell and viscose-type fibres, Eur. Polym. J., 40 (9), 2229-22034.

[15] O'Connor, R.T., DuPré, E.F., and Mitcham, D., 1958, Applications of infrared absorption spectroscopy to investigations of cotton and modified cottons, Text. Res. J., 28 (5), 382-392.

[16] Hurtubise, F.G., and Krassig, H., 1960, Classification of fine structural characteristics in cellulose by infrared spectroscopy. Use of potassium bromide pellet technique, Anal. Chem., 32 (2), 177-181.

[17] Nelson, M.L., and O'Connor, R.T., 1964, Relation of certain infrared bands to cellulose crystallinity and crystal lattice type. Part I. Spectra of lattice types I, II, III and amorphous cellulose, J. Appl. Polym. Sci., 8 (3), 1311-1324.

[18] Nelson, M.L., and O'Connor, R.T., 1964, Relation of certain infrared bands to cellulose crystallinity and crystal lattice type. Part II. A new infrared ratio for estimation of crystallinity in cellulose I and II, $J$. Appl. Polym. Sci., 8 (3), 1325-1341.

[19] Oh, S.Y., Yoo, D.I., Shin, Y., Kim, H.C., Kim, H.Y., Chung, Y.S., Park, W.H., and Youk, J.H., 2005, Crystalline structure analysis of cellulose treated with sodium hydroxide and carbon dioxide by means of X-ray diffraction and FTIR spectroscopy, Carbohydr. Res., 340 (15), 2376-2391.

[20] Spiridon, I., Teaca, C.A., and Bodîrlău, R., 2011, Structural changes evidenced by FTIR spectroscopy in cellulosic materials after pre-treatment with 
ionic-liquid and enzymatic hydrolysis, Bioresources, 6 (1), 400-413.

[21] Poletto, M., Ornaghi, H.L., and Zattera, A.J., 2014, Native cellulose: Structure, characterization and thermal properties, Materials, 7 (9), 6105-6119.

[22] Neto, W.P.F., Silvério, H.A., Dantas, N.O., and Pasquini, D., 2013, Extraction and characterization of cellulose nanocrystals from agro-industrial residue - Soy hulls, Ind. Crops Prod., 42, 480-488.
[23] Gümüskaya, E., Usta, M., and Kirci, H., 2003, The effect of various pulping conditions on crystalline structure of cellulose in cotton linters, Polym. Degrad. Stab., 81 (3), 559-564.

[24] Kim, H.S., Kim, S., Kim, H.J., and Yang, H.S., 2006, Thermal properties of bio-flour-filled polyolefin composites with different compatibilizing agent type and content, Thermochim. Acta, 451 (1-2), 181-188. 